\title{
Factors affecting the way students collaborate in a wiki for English language learning
}

\author{
Vida Zorko \\ University of Ljubljana
}

\begin{abstract}
Wikis are believed to be a powerful tool assisting the development of constructivist learning environments, as their very nature supports collaboration. However, not much research has been done into the types of collaborative interaction that take place in wikis when used for learning. The main purpose of this study is to explore the factors that affect the ways students collaborate in the wiki environment. To this end, a qualitative exploration of students' perceptions of collaboration in the wiki was carried out among sociology students at university level who used this environment in blended, problem based learning as part of their English for Specific Purposes course. The research shows that the wiki promoted many collaborative behaviours among students, such as learning from each other and communicating with the teacher. However, the data indicate that the wiki was less successful in facilitating other types of collaboration, such as communicating with peers and co-constructing products, primarily because the students had the opportunity to collaborate in live meetings and preferred to use Messenger and email to communicate. Overall, the results obtained here confirm that the wiki can be used to enhance effective collaboration in a constructivist approach to language learning.
\end{abstract}

\section{Introduction}

With rapid advances in Internet technologies an ever increasing choice of tools can be used to support language teaching. One such application that is used by educators to enhance constructivist teaching approaches is a wiki. A wiki is a web based publishing tool that offers learners and teachers an easily editable virtual space for sharing information and knowledge. It is believed to be particularly suitable for collaborative learning. The term collaboration is frequently associated with new and effective approaches to learning. It has also become very popular with the promoters of new technologies who have been using the term 'collaborative' to refer to any correspondence or coordination web tools to the extent that some educators fear it might lose its meaning (Roschelle \& Pea, 1999, p.23).

This study attempts to shed some light on collaborative interactions in the wiki environment in order to find out whether this environment facilitates effective, collaborative language learning and to identify some factors that affect the presence or absence of collaborative behaviours in the wiki.

\section{Online collaboration}

Learning in the educational community helps students become independent thinkers and collaborative learners, which are qualities that are required to meet successfully the challenges of today's knowledge society (Garrison \& Anderson, 2003, p.22). 
Collaborative work is thus a key component of scholarly activities in educational communities which are using new social networking tools and developing new forms of interaction in virtual worlds (The Horizon Report, 2007, p.5). Computers are increasingly viewed as doors to social spaces (Oblinger, 2005, p.71), and many believe that the social nature of Web 2.0 technologies supports collaboration (Godwin-Jones, 2003, p.15).

Collaborative technology is any application that 'enables and scaffolds the construction of communal ways of seeing, acting and knowing, and production of shared knowledge and new practices for successful future action' (Lipponen \& Lallimo, 2004, p.436). However, technology itself does not guarantee a good education (Sikkel et al., 2002, p.26). Merely preparing the software and informing the learners that they can use it does not mean that the teacher has developed a collaborative learning environment, because the students may not use it (Brook \& Oliver, 2003). Collaborative software can be useful but it cannot produce group collaboration, it can only facilitate it (Hiltz, 1998).

The language teacher who uses collaborative technology has to design such tasks for the virtual environment that correspond to activities students will perform outside it. It is also important that students themselves see how these tasks relate to activities outside the classroom (Chapelle, 2001, p.80). The teacher will achieve successful second language acquisition if they consider the social and affective aspects of learning. Thus, an important goal of the language learning process is to develop the students' interest in looking for opportunities for communication and the willingness to communicate in them. This will depend on many factors such as the student's personality, social situation, communicative competence, the desire to communicate with a particular peer, etc. (Chapelle, 2001. p.50).

\section{Characteristics of online interaction}

The literature search revealed that different authors operationalise collaboration differently and that they list different elements as constituting collaborative learning. In an attempt to classify these elements, Curtis and Lawson's (2001, p.23) four types of interaction in collaborative learning were used as categories. Curtis and Lawson (2001) distinguished interaction with peers, with the teacher, with resources and, in an online environment, with an interface. They claimed that for online collaboration to be effective, all four types of interaction have to be effective. Below is a list of elements found in the literature, which is by no means exhaustive. The elements broadly fit into one of the four types of collaborative interaction.

\section{Characteristics of peer to peer interaction in effective collaboration:}

- synchronous and interactive building of a joint solution to a problem, reaching a shared, common goal (Beatty \& Nunan, 2004; Curtis \& Lawson, 2001, p.22; Murphy, 2004, p.423; Neo, 2004) and producing shared artefacts (Murphy, 2004, p.423);

- engagement in small group skills (Johnson \& Johnson, 1998) and building teamwork (Arnold \& Ducate, 2006, p.43);

- genuine interdependence between the students (Wasson \& Mørch, 2000, p.238);

- fair distribution of work so that every group member contributes effectively (Alonso et al., 2005; Wasson \& Mørch, 2000, p.238);

- monitoring each others' efforts in order to improve the effectiveness of group members' contributions (Johnson \& Johnson, 1998); 
- helping each other to achieve the group goal (Alonso et al., 2005; Johnson \& Johnson, 1998; Neo, 2004);

- giving and receiving constructive feedback in the form of advice and encouragement (Alonso et al., 2005, p.230; Johnson \& Johnson, 1998; Neo, 2004);

- planning and initiating further collaborative activities (Curtis \& Lawson, 2001, p.29);

- acquisition of knowledge, skills and attitudes (Lea et al., 2002, p.54);

- critical thinking (Arnold \& Ducate, 2006, p.43);

- exchanging knowledge resources, information and ideas (Bednar et al,. 1992, p.28; Johnson \& Johnson, 1998; Neo, 2004; Salmon, 2002, p.144; Wasson \& Mørch, 2000, p.238);

- exchanging, comparing and understanding perspectives on issues (Karagiorgi \& Symeou, 2005, p.21; Miller \& Miller, 1999, p.111; Murphy, 2004, p.423) and coconstructing new perspectives and meanings (Murphy, 2004, p.423);

- a joint reflection on the progress of their work (Curtis \& Lawson, 2001, p.22);

- teaching each other (Johnson \& Johnson, 1998; Kennedy \& Duffy, 2004, p.208);

- a discussion where students challenge each other (Johnson \& Johnson, 1998; Miller \& Miller, 1999, p.111), explain and elaborate information (Curtis \& Lawson, 2001, p.29);

- a willingness to listen to the ideas, suggestions and views of others (Beatty \& Nunan, 2004, p.166; Miller \& Miller, 1999, p.111);

- the presence of social elements in students' interactions in online interactions that supplement face to face interactions (Curtis \& Lawson, 2001, p.26);

- commenting on the medium and its features in online interactions (Curtis \& Lawson, 2001, p.26);

- autonomous learning (Arnold \& Ducate, 2006, p.43);

- well-defined self identity vis-à-vis other group members (Lea et al., 2002, p.55);

- a clearly defined group identity (Lea et al., 2002, p.55) and a sense of community (Murphy, 2004, p.422); and

- an intergroup comparison of work and progress (Lea et al., 2002, p.57).

Characteristics of student-teacher interaction in effective collaboration:

- one to one interactions and consultations with the teacher (Curtis \& Lawson, 2001, p.23);

- the teacher's immediate feedback to students in the form of guidance, support and advice when needed (Alonso et al., 2005, p.230; Curtis \& Lawson, 2001, p.23; Neo, 2004);

- the teacher's facilitation of the student's learning process (Choy \&Ng, 2007; Hiltz, 1998; Schneider, 2003, p.3);

- the teacher's provision of intellectual and emotional support to students (Alonso et al., 2005);

- the teacher's breaking up of large phases into smaller sub-phases to help students do things in the right order and to manage things (Schneider, 2003, p.6);

- the teacher's managing of the 'delicate balance between letting the students be free and guiding them' (Schneider, 2003, p.3); and

- the teacher's training of students in learning strategies as part of the learning process (Beatty \& Nunan, 2004, p.182).

\section{Characteristics of student interaction with the resources in effective collaboration:}

- the provision of a scaffolding to aid thinking and problem solving (Arnold \& Ducate, 2006, p.43; Beatty \& Nunan, 2004, p.181; Curtis \& Lawson, 2001, p.31). This 
can be done with prompts, hints, explanations, questions and suggestions (Arnold \& Ducate, 2006, p.43); and

- the provision of a 'script' specifying the tasks students have to do, the composition of groups, distribution of tasks, the timing, the order of individual phases etc.

(Schneider, 2003, p.3).

Characteristics of student interaction with the interface in effective collaboration:

- absence of technical problems in collective network environments and user friendly use (Lindblom-Ylänne \& Pihlajamäki, 2003, p.27);

- freedom to control access to information and contents (Miller \& Miller, 1999, p.111);

- freedom to select the sequencing of contents (Miller \& Miller, 1999); and

- the inclusion of some instructional elements to prevent learners from getting lost (Miller \& Miller, 1999).

It is believed that online environments can provide opportunities for collaborative interactions. Strengths and problems of online collaboration are the subject of the sections below.

\section{Strengths of collaborating online}

Research shows that there is some effective collaboration online (Curtis \& Lawson, 2001; Hiltz, 1998) and that emotional support, sociability, information and instrumental aid can be provided in online communities (Hiltz, 1998). It is also evident that collaborative online learning environments are particularly suitable for Net Generation learners who have grown up with and used the Internet all their lives (Oblinger, 2005, p.71). Thorne and Payne (2005, p.379) call them 'digital natives' or 'NGeners'. What they expect and want from learning technology is interactivity, be it with a computer, a teacher or a classmate (McNeely, 2005).

Another advantage supported by research is the time lag in communication offered by asynchronous collaborative tools such as wikis. This temporal delay gives the reader time to reflect before posting a reply. It thus connects students regardless of time and space (Arnold \& Ducate, 2006, p.43-44). Hiltz (1998) believed that the absence of time and space constraints leads to more interaction. Her findings show that asynchronous collaboration brings effective results in terms of 'learning, quality of solution, solution content, and satisfaction with the solution quality'.

\section{Problems of collaborating online}

Several researchers report problems students have had when collaborating online. Hiltz (1998) found that students were not very satisfied with the process of group interaction and quality of group discussion. She also mentioned the problem of waiting for feedback can lead to a lack of a social presence. The same problem is also identified by Arnold and Ducate (2006, p.44). However, they also found that the lack of immediate feedback can be positive because it enables students to think more and produce better and more succinct and meaningful messages. In addition, the recording of messages motivates students to write better (Arnold \& Ducate, 2006).

O'Donoghue et al. (2001, p.514) refer to some authors who fear that a deep understanding and valuable skills such as teamwork and presentation cannot be acquired via the web and that face to face interaction with the teacher and peers is 
necessary. Similarly, Johnson and Johnson (2004, p.805) argue that technology rarely engages students in intellectual conflict the same way other students can'. This is echoed by Roschelle and Pea (1999, p.23) who doubted that the web can promote higher order skills. They believed that there are some more effective ways of promoting these skills and that the web's capacity for collaboration is exaggerated because some collaborative interactions are hard to reproduce in an online environment.

The online technologies that the teacher can apply in online collaborative learning are abundant, ranging from the first generation web tools that include web pages, email, chat rooms, discussion boards, voice-based forums, learning management systems, webcams, to the second generation web or Web 2.0 tools such as blogs, podcasts and wikis.

\section{Learning in wikis}

Wikis are shared workspaces that appeared in the mid-1990s (Wei et al., 2005, p.204) and have been gaining popularity ever since. They are a collection of interlinked webpages that can be easily edited and freely expanded by any user. They have many practical features such as password protection, logging of changes to allow a tracking of the editing process, the possibility to revert to earlier versions of wiki pages, and user authentication which enables the easy tracking of wiki edits and identification of authors. Users can visit, read, reorganise and update the structure and content of wiki pages as they see fit.

The literature points to the following wiki characteristics that make them appropriate for uses in education:

- user friendliness: Wikis are robust, simple, easy to use, constantly updated by the providers, require no technical knowledge and can be used by a very large number of users.

- flexibility: The information and resources in wikis are available and easily accessed at any time from anywhere (Augar et al., 2004, p.95; Nicol et al., 2005, p.35), and can be reused by future cohorts of students, which reduces the repetition of information and information searching (Nicol et al., 2005, p.35).

- low cost: There are minimal costs in terms of purchasing, maintenance, support and the teacher's time.

Wikis can be used by teachers to enrich and supplement (online) learning (Choy and $\mathrm{Ng}$, 2007). Their potential uses in higher education are many but they seem to be especially suited to:

- storing different types of digital information: In wikis information such as class instruction documents, reports, web links, ideas, sketches etc. is easily stored (Nicol et al., 2005), and wikis can function as archives of a community's practices (Choy and $\mathrm{Ng}, 2007$ ) that are later used as repositories of knowledge by new students (Beldarrain, 2006, p.148; Godwin-Jones, 2003, p.15);

- sharing information (Augar et al., 2004, p.95; Nicol et al., 2005, p.35): The public visibility of students' work facilitates sharing of information, resources and ideas;

- monitoring students' group or individual progress (Nicol et al., 2005, p.35): By monitoring student participation, the teacher can more readily assess students' work (Augar et al., 2004, p.98); 
- promoting democratic participation (Schwartz et al., 2004, p.2): The nature of wikis permits very easy and free access to any student who has been entrusted with the password which encourages the participation of all students;

- empowering students: The freedom to create, change or delete anything empowers students with more responsibility (Thorne and Payne, 2005, pp.383, 384);

- interacting socially and collaborating (Augar et al., 2004, p.95; Choy and Ng, 2007; Godwin-Jones, 2003, p.15; Schwartz et al., 2004, p.2; Thorne and Payne, 2005, p.381; Wei et al., 2005, p.205): The possibility of the students' use of wikis to fundamentally change their own knowledge constructions and develop a deeper understanding of concepts through transformative dialogue and the construction of new knowledge makes wikis 'transformative software' (Kennedy and McNaught, 1997).

Despite an increasing number of authors who argue that the implementation of wikis in the teaching process helps facilitate collaborative learning, Choy and $\mathrm{Ng}$ (2007) feel there is a lack of empirical research in this area.

\section{The learning context and the aim of the research}

The focus of this study is collaboration in a wiki that was introduced in the 2006/2007 academic year to support the teaching of the English for Specific Purposes 2 course at the Faculty of Social Sciences in the University of Ljubljana. The wiki was used with ten cohorts of about 40 full time, second year sociology students who had an advanced English language proficiency level and good Internet skills. Most of them had access to a computer and the Internet.

The wiki, which may be accessed at http:/ / fdvenglish2pbl.pbworks.com/, contains a welcome page with links to individual group pages. These have templates that scaffold the students' editing but they are allowed to personalise and modify them as they see fit (see Figure 1).

Each wiki page contains a side bar with links to useful resources such as guidelines for minutes and report writing. The wiki was conceived to provide a virtual space in the context of blended, problem based learning (PBL) where students work in small groups to solve an open ended, real life problem. Group work involved doing research, holding meetings, creating products such as minutes of meetings and submitting them by determined deadlines, writing the research report and presenting it in class.

The PBL experience prior to introduction of the wiki showed a few problems. First, the students needed more immediate feedback on their progress and more communication with the language teacher than the scheduled hours permitted; second, not all the students were able to participate fully in group learning due to time and space constraints; third, some groups lacked motivation to create quality products; fourth, knowledge sharing among students and groups of students was poor; fifth, students' contributions were sometimes difficult to assess; and sixth, some students did not take full responsibility for their personal and their group's success.

The creation of the wiki as an additional PBL environment substantially improved all the six problem areas. I was able to provide timely support and guidance to all the groups; the students reported easier communication within the group and better participation in group learning; the visibility of the student work contributed to more 
effort to do well; the public nature of the wiki facilitated the sharing of information, resources and knowledge; the wiki feature that displays the history of editing enabled an easier assessment of students' contributions; and the availability of all the necessary resources in the wiki resulted in greater student responsibility. In addition, the students' end of course evaluation revealed that the PBL process and the use of the wiki were perceived as a positive experience.

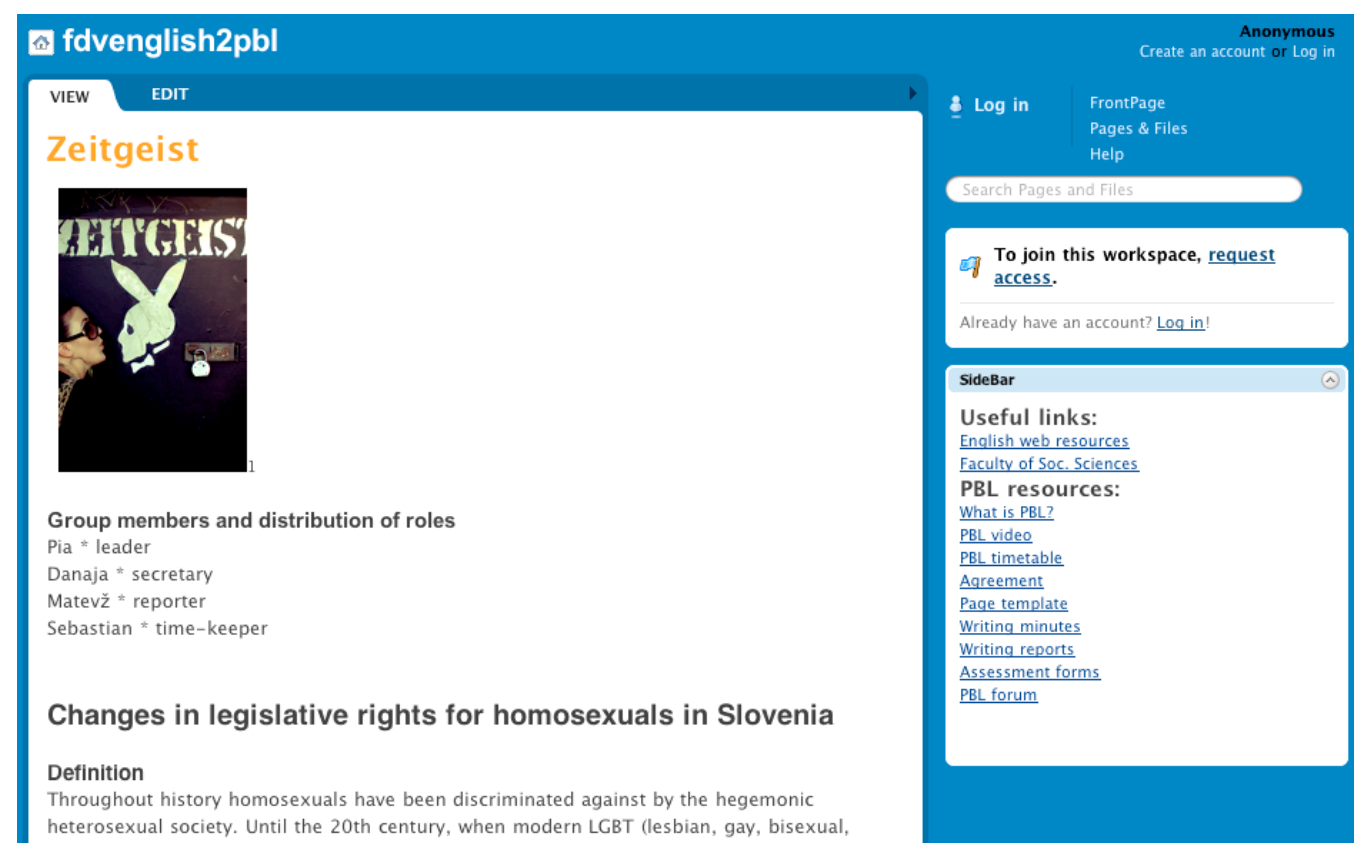

Figure 1: A group page in the wiki

All the above mentioned improvements of the PBL process and products that I have noticed from the teacher's perspective as well as the students' positive feedback on the experience with the wiki suggested that the wiki may indeed be helpful in promoting collaborative behaviours. For this reason, I wanted to gain an insight into the factors that promote these behaviours. Thus, the main question of interest was:

- Which factors affect the ways students collaborate in the wiki?

In addition I framed the following hypotheses in relation to collaboration in the wiki:

- The wiki promoted peer interaction.

- The wiki promoted student-teacher interaction.

- The student interaction with the resources in the wiki was beneficial.

- The wiki software was easy to interact with and aided collaboration.

\section{Research methodology}

In order to explore the way students collaborated in the wiki and to test the hypotheses the case study method was adopted. Three students were selected as cases on the basis of the retrospective data obtained through the PBL process, the wiki editing history 
and the answers to the questionnaire that had been sent to the PBL group members. In the questionnaire with closed-ended questions, the students had to evaluate 39 statements about their collaboration in the wiki (see Appendix 1). The statements were grouped in four sections based on the four types of interactions in effective collaborative learning (see the section 'Characteristics of online interaction' above). The students evaluated the statements using a five-point Likert scale. The range descriptors were from 'strongly agree' to 'strongly disagree' and from 'very useful' to 'not at all useful'. The purpose of the questionnaire was to obtain some initial insight into patterns of collaboration on the basis of which the three students would be selected as cases and candidates for the interview. The selection was made by comparing the questionnaire answers with data from the groups' wiki pages and assessment results, on the basis of which the three most interesting cases were chosen. The participants are referred to using imaginary names and the feminine pronoun to ensure their anonymity.

"Barbara" was chosen and invited for the interview for the following reasons. Her group had an excellent overall performance of PBL tasks, received a good grade and was always among the best groups that completed the assignments perfectly and always met the deadlines. They also had one of the best wiki pages (see Figure 2) and the history of page edits showed the very lively activity of all members of the group with one of the highest numbers of edits (117 per group). Yet, out of the students who returned the questionnaire Barbara perceived the wiki the least as being supportive of collaboration.

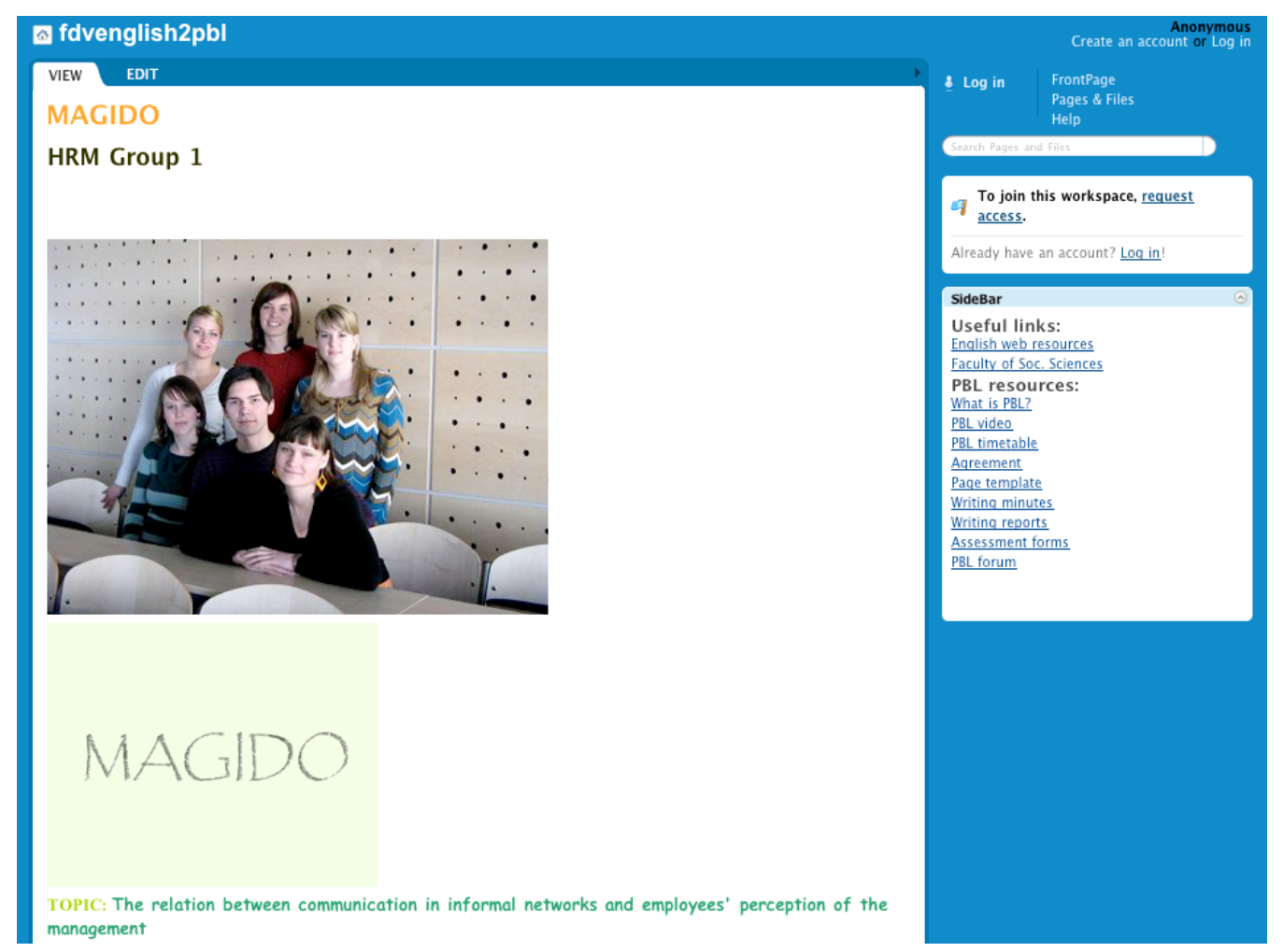

Figure 2: A snapshot from Barbara's group page 
"Irene" was selected for the interview because her group had some problems completing the assignments on time at the beginning of the PBL process. Although all members edited their wiki page, they had one of the lowest numbers of page edits (58) compared to other groups. Nevertheless, Irene perceived the interactions in the wiki as very beneficial for collaboration. It was also evident that eventually the group improved their performance and received a fairly good grade. Their group page was well prepared and it was also interesting that they made use of the wiki's 'Comments' facility to ask questions and arrange things (see Figure 3).

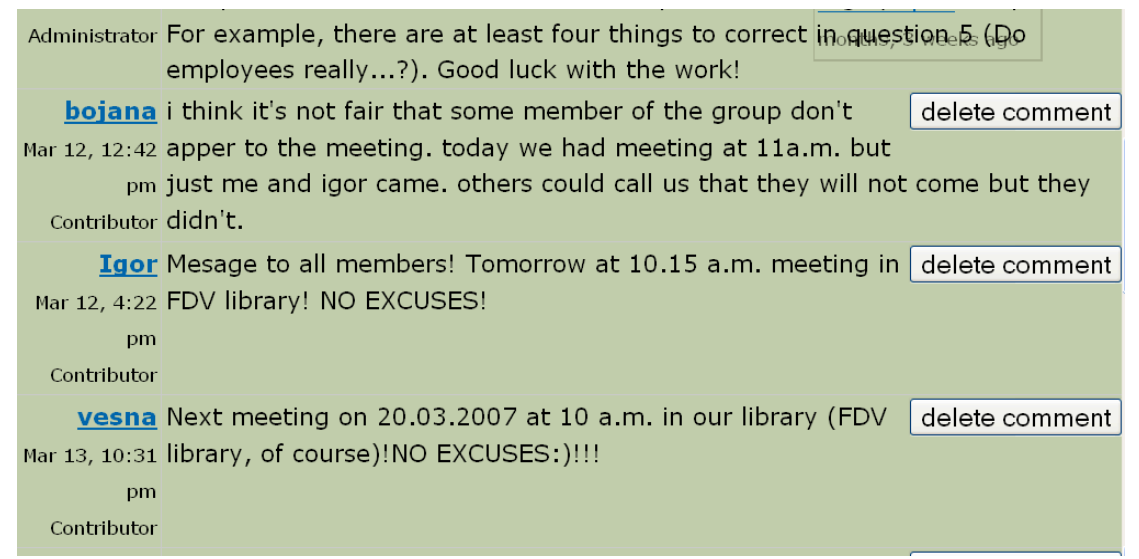

Figure 3: A snapshot from Irene's group space for comments

"Anna" seemed an interesting case because her group had an excellent group performance, that is, they met all the deadlines, carried out all the PBL steps very well and received a very good grade. In the questionnaire she gave the highest grades of all the respondents. In contrast, their group page was very simple compared to the others with minimal chat activity in it. Moreover, the history of the page showed very few wiki edits (63) with two members doing most of the editing (see Figure 4).

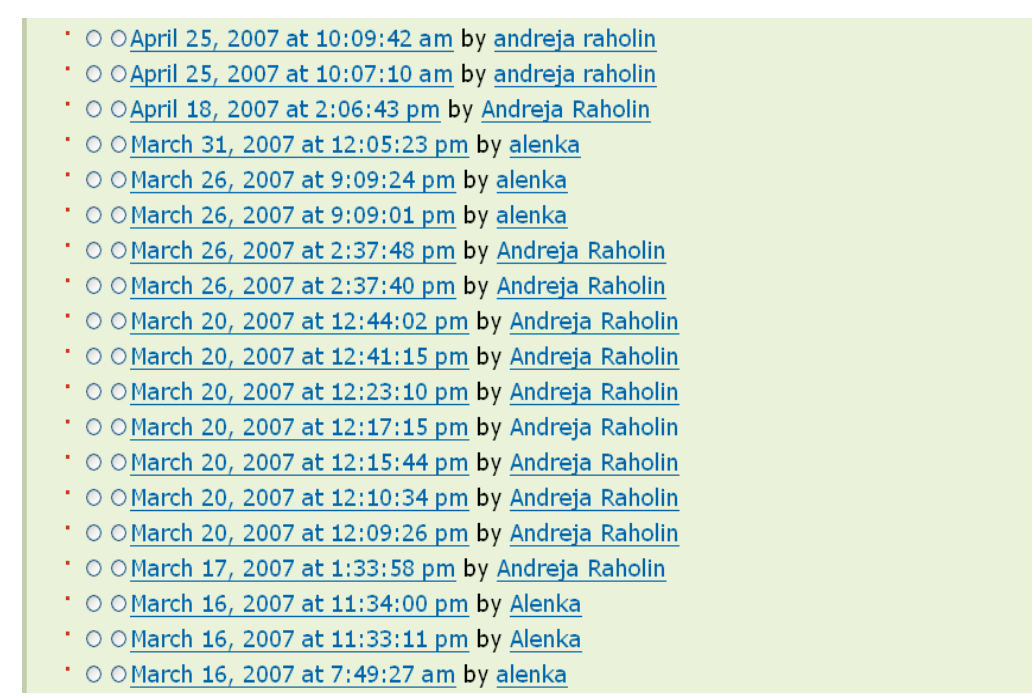

Figure 4: A snapshot of the editing history of Anna's group page 
The three selected students were invited for the face to face semi-structured interview (see the questions in Appendix 2). They were interviewed separately to assure privacy, confidentiality and comfort.

\section{Data analysis and interpretation}

In the qualitative analysis of the verbatim interview transcripts the initial themes were identified and the answers of the three participants were grouped to facilitate a comparison. In the descriptive analysis substantive content was looked for, the categories were refined and portions of content were grouped to them. The descriptive analysis started while summarising the transferred text in the data management stage. Care was taken not to pick out the more interesting features and thereby distort the account or select only that evidence that would support my preferred conclusion (Cohen et al., 2000, p.182).

The explanatory analysis helped to find patterns and links between the phenomena. Obvious relations were looked for, for example, the motivation to do well and being publicly visible. The underlying logic was uncovered in the process of explaining the links. The aim was to achieve some internal validity in order to gain a deeper insight into and understanding of the particular cases (Nunan, 1990, p.80).

\section{Analysis of collaborative interactions in the wiki}

This part looks at some of the collaborative behaviours that the students mentioned in the interview and the reasons these behaviours were present or were not present in the wiki. It analyses the respondents' answers according to the characteristics of the four types of interaction in effective collaborative learning that were dealt with in the section 'Characteristics of online interaction'.

\section{Interaction with peers}

Comparing work and learning from each other

With regard to peer interaction, all three respondents found the wiki extremely convenient for comparing their work with the work of other groups and learning from each other. This is because of the opportunity to be constantly able to see how other groups were tackling the tasks. The wiki pages of other groups provided the students with a useful additional resource. They read them to see if they were moving in the right direction, to see what others had produced, what comments whey wrote or received from the teacher or checked them to see if there was anything new or relevant to their own work.

Anna: The best thing was that we could see what the others were doing, to have some sort of overview of your own work and the work of other groups... Or that you learn from others, that others see your mistakes...

Being motivated

This public nature of the wiki was a strong factor of motivation to do better.

Barbara: This [public nature of the wiki] was definitely motivating!

Two other factors of motivation to do well in the wiki were the awareness of the assessment and the teacher's encouragement. 
Anna: Yeah, the deadlines were obligatory and we followed that. And also the encouragement from your part.

Defining group identity

For Barbara the public nature of the wiki was an opportunity to have her group identity better defined in relation to other groups. This was also enabled by the wiki's feature of adding pictures, documents and links.

Barbara: We liked it that we, apart from publishing text, we could also add pictures and stuff, so that we could make the page a bit more original.

Using Messenger and email

For communication the interviewees preferred Messenger, email and mobile phone because these technologies have become an integral part of their everyday lives and they enable immediate contact.

Barbara: Actually we used Messenger to discuss things.[...] And if there was something urgent, we would use the phone.

The interviewees felt that they and their peers did not really construct things together in the wiki. Anna and Irene's groups preferred to use email to send each other versions of products. By email they commented on and corrected the products and then finally published the final version of them in the wiki.

Irene: ... we consulted each other via email or any other way and then the final version was published in the wiki.

Barbara said that her group also used email but mostly composed all the documents together in their face to face meetings because they wanted to finish things quickly and thoroughly.

Barbara: We actually composed everything together at the meetings, we all checked it together. [...] We hated it if things were done halfway through, right...

The interviewees and their peers thus did not use the potential of the wiki for transparent co-construction things. They preferred face to face, individual or email collaboration.

\section{Using English}

As evidenced above, the interviewees and their peers preferred a more immediate and direct way of communicating to get things done faster and therefore mostly used Messenger or email to discuss things using the Slovenian language. They believed they would have also communicated in the wiki using English if it had had a chat application.

Anna: What we talked about [through Messenger] was not really academic language

[...] I think we could've done it just as easily in English.

The English language thus did not seem to be a hindrance for the respondents but they were simply more used to using other technologies for communicating where the use of Slovenian was a logical choice. Interestingly, in my email correspondence I also noticed that with the introduction of the wiki the students spontaneously started to write their emails to me in English when they asked for help. 
Distributing work in the wiki

The interviewees said that the distribution of work in the wiki was spontaneous. One would offer to take on responsibility for a certain task and the other members would agree. The reasons for volunteering were the fear that the peers would not do the task well, the peers' liking what one member did and thus assigning the wiki work to him or her, or the enjoyment in using the wiki.

Irene: I took on responsibility for this [the wiki page]. Because I felt, I don't know, maybe... I was afraid that things wouldn't be done as they should be.

Commenting on technical aspects of the software in the wiki

The interviewees did not feel that they would comment on the wiki's features in the wiki itself but the retrospection showed that they did occasionally post comments asking for help if they could not edit the wiki the way they wanted. Below is an example from Anna's group wiki page where they talked about the editing feature and a problem connected to it:

Andreja: Sorry, I deleted another frame. I don't know how to change it back :(

\section{Interaction with the English teacher}

The respondents all said that the wiki helped them to communicate more and more effectively with the English teacher. They listed reasons such as the teacher replying fast, the ability to read the teacher's comments given to other groups and the teacher's encouragement to post comments. Such immediate feedback helped them progress with the work faster.

Barbara: We were absolutely thrilled, surprised in a positive way because you were replying very fast to our questions...

Anna: You also encouraged us non-stop in class [...] I wasn't afraid that I would look stupid if I asked a silly question...

Irene: I think that this relationship between you and us was very good. Whatever we needed, we got it... help.

\section{Interaction with the resources}

The interviewees found the resources in the wiki helpful. For example, the Writing reports resource was used a lot because the students could check the elements of the report and the structure while they were writing it. Some resources were used only at the beginning of the project or at the end when the students printed them off and filled them in. The respondents thought the wiki contained all the necessary resources.

\section{Interaction with the software}

For the interviewees, the wiki software was easy and interesting to interact with and they had no problems using it. In addition, they saw using the wiki as a skill that would be useful to learn for the future.

Barbara: Ooooh, easy! I mean... it's really simple, right.

Irene: Something we will definitely have to use in the future...

Barbara also found the technology to be an additional source of motivation.

Barbara: It was interesting because it was something new. 
The interviewees had no problems finding their way around the wiki and liked the way the pages and resources were interlinked.

Irene: Everything was alright, clear and logical.

Occasionally there were some minor technical problems that made the respondents frustrated. One of them was not being able to always save the selected choice of fonts or design.

\section{Discussion and recommendations}

The aim of this study was to gain an insight into factors that promoted or hindered collaborative behaviours in the wiki. The purpose was to evaluate the collaborative affordances of a wiki set up to provide an additional space for problem based language learning in order to make it more suitable for collaboration. It was hypothesised that the wiki would promote peer to peer and student-teacher interaction, that the students would engage with and benefit from the wiki resources, and that interacting with the wiki application would be easy enough to support collaboration. The research showed that the wiki did effectively promote some collaborative behaviours but was less successful in facilitating others. It also illuminated some of the reasons for the presence or absence of these behaviours. This section first discusses the major factors that impacted on the students' collaborative interactions in both positive and negative ways. It concludes with a set of recommendations on how to enhance the students' collaboration in the wiki.

\section{The factors that enhanced collaboration in the wiki}

The visibility of everyone's work

The analysis of the interview data shows that the wiki facilitated a comparison of the students' own work with the work of other groups and learning from each other. The reason for that was the students' continuous opportunities to see how the other groups were tackling the tasks, what they had produced and what comments they had written to or received from the teacher. This helped the students check if they were moving in the right direction, learn from better groups how to do things correctly, get ideas and follow the advice the teacher had given to other groups. They could also learn from the mistakes other groups had made which helped them not to repeat the same ones. The visibility of everyone's work in the wiki promoted the students' effort to do better because the students did not wish to have the most boring page or they wanted their wiki page to be the best and most outstanding.

The teacher's prompt response and encouragement

The wiki environment was very successful in facilitating interaction with the English teacher. One reason mentioned was that the teacher responded promptly to the students' queries, or reacted immediately if there was a problem, so that the students had immediate feedback. Another reason was the teacher's encouragement to use the wiki when in need of guidance or advice so that the students did not feel ashamed to publicly ask for help. The teacher also encouraged the students to perform the tasks well, which the students found motivating.

\section{Accessibility of resources and scaffolding}

There was also a lively interaction with some of the resources in the wiki. Their organisation helped scaffold the work. They provided the students with templates 
during the writing process and offered direction. Some hyperlinked documents were only visited at certain times during the process when the students needed to print them off, sign or fill them in and submit them to the teacher. The availability and scaffolded nature of the resources promoted their use.

\section{User friendliness}

The wiki used by the students is a PBworks clone whose editing features seemed to be very user friendly and interesting to explore. By providing features such as uploading pictures it enabled the groups to better form their group identity vis-à-vis other groups. The students were motivated by the novelty of the application and because they believed that knowing how to use the wiki is a skill they will need in the future. They found the teacher's explanations of the work in the wiki helpful. The students could easily find their way around the wiki and its organisation was clear and logical to them.

\section{Assessment}

Another source of motivation to collaborate more in the wiki was the students' awareness that the process and products of work would be assessed.

\section{The factors that inhibited collaboration in the wiki}

Frequent face to face meetings

The interview with the three students indicated that they did not use the wiki environment for communication with the group members because they had an opportunity to meet face to face and did not need to collaborate from different locations. For this reason much of peer to peer communication and co-construction of knowledge and products took place live.

Preference for Messenger, email and mobile phone communication

Apart from live meetings, the students collaborated via Messenger, email and mobile phone because these technologies facilitate immediate contact with two or more peers, the students are more used to them and find them to be the fastest way of solving problems. They are logged on to Messenger all day and check their emails regularly. These technologies thus form part of the students' everyday life.

\section{Technical glitches}

The students said they were occasionally annoyed by technical glitches in the wiki. Sometimes they could not save the edits in the selected font or colour.

\section{Preference for publishing only the finished product}

In Anna's group the students mostly published only finished versions of the products. A reason for collaborating on products outside the wiki environment mentioned by Barbara was her group's dislike of having things done only partially. In her group the students had a strong preference for publishing only perfectly finished products.

\section{Recommendations for improving the wiki}

On the basis of the data generated in this study a number of recommendations can be made on how to increase collaborative behaviours in the wiki:

1. Select user friendly wiki software: Select a wiki clone that is reliable and user friendly to minimise any technical difficulty. The wiki has to provide features such as uploading pictures so that the groups can personalise their group space. 
2. Organise the wiki clearly: Make the wiki easy to use by organising the contents and links clearly and logically so that the students can easily find their way around.

3. Provide all the necessary resources: Carefully select, prepare and scaffold the resources the students need during the project so as to make the wiki function as a portal to a selected collection of all resources and links to databases needed for the successful completion of PBL projects. In this way the students will be able to complete the project easier and faster.

4. Teach using the wiki features: The students will use the wiki better if you show them what they can do with it.

5. Make the students aware that their contributions in the wiki are part of assessment: Make it clear to the students that the process and products of work in the wiki will be assessed.

6. Build a positive relationship with the students: Foster a good and friendly relationship with the students and inspire a positive attitude to work in face to face sessions as well as in the wiki. This will motivate the students to collaborate better in the wiki.

7. Encourage asking for help: For the students to be bold enough to publicly ask for help, encourage them to ask questions publicly without feeling ashamed.

8. Facilitate the building of a group identity: Allowing the groups to have the possibility to organise their pages in an original way will help the groups build a stronger group identity.

9. Make all the group's work visible and easily accessible: In this way the students will be able to learn from each other by comparing each other's products. They will be able to see how the other groups engage in the tasks, read what they write and check if they are progressing well. They will get ideas and learn from the good work of better groups as well as from the mistakes of the weaker ones. They will be able to read and follow the advice the teachers give to the other groups. Knowing that other people will read their work will make the students more motivated to do their best.

10. Promote using the wiki for communication and collaboration in English: There are a few ways to promote peer communication and collaboration in the English language. One way is to intensively encourage the building of a virtual community space in the wiki to make the students get used to it. In their research on collaborative portal sites, Schneider et al. (2004, p.20) suggested that this can be done by refusing to answer questions by email and insisting that the students use the community features until they become so used to them as they are used to email that they begin to feel 'at home'. Alternatively, encourage the parallel use of email and teach email communication in English. A third way, suggested by the participants in this study, and perhaps the best way to get the students to communicate more in English, is to add a chatroom or forum to the wiki. This research showed that the students are used to these applications and would communicate in them in English.

11. Offer prompt feedback: Monitor the students' progress to immediately spot if the students are having a problem. By offering timely support and feedback, the students will be able to move forward with their work faster and achieve better results. Leaving comments for one group will be beneficial to all the students 
because they will be able to see and read them. The value of this kind of support cannot be substituted with face to face classroom feedback because the latter comes with a substantial time lag.

Following these recommendations the teacher will be able to create conditions favourable to the students' collaborative interactions with their peers, teacher, resources and software.

In conclusion, the study of the students' perceptions of the wiki's suitability for collaborative, problem based language learning confirmed all four initial hypotheses. The wiki did promote peer and student-teacher interaction, the students' interaction with the hyperlinked resources and the software was beneficial and supportive of collaboration.

The study provided some valuable insights into the types of interaction that took place in the wiki, and some understanding of the meaning the students ascribed to these interactions. It illuminated some of their attitudes, motivations, problems and expectations with respect to problem based language learning in the wiki environment. The new understanding of the wiki's strengths and weaknesses in providing affordances for collaborative learning of the English language will help to inform future improvements of the wiki in question to make it pedagogically better suited for the constructivist approach to English language learning.

\section{Acknowledgments}

I sincerely thank Susan A. Brown for her invaluable support and kind encouragement.

\section{References}

Alonso, F., López, G., Manrique, D. \& Viñes, J.M. (2005). An instructional model for web-based e-learning education with a blended learning process approach. British Journal of Educational Technology, 36(2), 217-235.

Arnold, N. \& Ducate, L. (2006). Future foreign language teachers' social and cognitive collaboration in an online environment. Language Learning $\mathcal{E}$ Technology, 10(1), 42-66. http:/ /llt.msu.edu/vol10num1/arnoldducate/default.html [viewed 9 April 2009].

Augar, N., Raitman, R. \& Zhou, W. (2004). Teaching and learning online with wikis. In Beyond the comfort zone: Proceedings ASCILITE Perth 2004 (pp. 95-104). Perth, 5-8 December. http:/ / www.ascilite.org.au/conferences/perth04/procs/augar.html

Beatty, K. \& Nunan, D. (2004). Computer-mediated collaborative learning. System, 32(2), 165-183.

Bednar, A. K., Cunningham, D., Duffy, T. M. \& Perry, J. D. (1992). Theory into practice: How do we link? In T.M. Duffy, \& D.H. Jonassen (Eds.), Constructivism and the technology of instruction: A conversation. Hillsdale, New Jersey: Erlbaum.

Brook, C. \& Oliver, R. (2003). Online learning communities: Investigating a design framework. Australian Journal of Educational Technology, 19(2), 139-160. http: / / www.ascilite.org.au/ajet/ajet19/brook.html

Chapelle, C.A. (2001). Computer applications in second language acquisition: Foundations for teaching, testing and research. Cambridge: Cambridge University Press. 
Choy, S.O. \& Ng, K.C. (2007). Implementing wiki software for supplementing online learning. Australasian Journal of Educational Technology, 23(2), 209-226. http:/ / www.ascilite.org.au/ ajet/ ajet23/ choy.html

Cohen, L., Manion, L. \& Morrison, K. (2000). Research methods in education (5th ed.). London: Routledge Falmer.

Curtis, D. D. \& Lawson, M. J. (2001). Exploring collaborative online learning. Journal of Asynchronous Learning Networks, 5(1). [verified 25 Oct 2009] http: / / www.aln.org/publications/jaln/v5n1/pdf/v5n1_curtis.pdf

Garrison, D. R. \& Anderson, T. (2003). E-learning in the 21st century: A framework for research and practice. London: Routledge Falmer.

Godwin-Jones, R. (2003). Blogs and wikis: Environments for on-line collaboration. Language Learning $\mathcal{E}$ Technology, 7(2), 12-16. [viewed 9 Apr 2009, verified 25 Oct 2009] http:/ /llt.msu.edu/vol7num2/ pdf/emerging.pdf

Hiltz, S. R. (1998). Collaborative learning in asynchronous learning networks: Building learning communities. Invited Address at WEB98. Orlando Florida. November 1998. http:/ / eies.njit.edu/ hiltz/collaborative_learning_in_asynch.htm [viewed 9 April 2009].

Johnson, D. W. \& Johnson, R. T. (1998). Cooperative learning and social interdependence theory. http:/ / www.co-operation.org/pages/SIT.html [viewed 9 Apr 2009].

Johnson, D. W. \& Johnson, R. T. (2004). Cooperation and the use of technology. In D. H. Jonassen (Ed.), Handbook of research on educational communications and technology. London: Lawrence Erlbaum.

Karagiorgi, Y. \& Symeou, L. (2005). Translating constructivism into instructional design: Potential and limitations. Educational Technology \& Society, 8(1), 17-27. http: / / www.ifets.info/journals/8_1/5.pdf

Kennedy, D. \& Duffy, T. (2004). Collaboration - a key principle in distance education. Open Learning: The Journal of Open and Distance Learning, 19(2), 203-211.

Kennedy, D. M. \& McNaught, C. (1997). Design elements for interactive multimedia. Australian Journal of Educational Technology, 13(1), 1-22. http:/ / www.ascilite.org.au/ajet/ajet13/ kennedy.html

Lea, M., Rogers, P. \& Postmes, T. (2002). SIDE-VIEW: Evaluation of a system to develop team players and improve productivity in Internet collaborative learning groups. British Journal of Educational Technology, 33(1), 53-63.

Lindblom-Ylänne, S. \& Pihlajamäki, H. (2003). Can a collaborative network environment enhance essay-writing processes? British Journal of Educational Technology, 34(1), 17-30.

Lipponen, L. \& Lallimo, J. (2004). Assessing applications for collaboration: From collaboratively usable applications to collaborative technology. British Journal of Educational Technology, 35(4), 433-442.

McNeely, B. (2005). Using technology as a learning tool, not just the cool new thing. In D. Oblinger (Ed.), Educating the Net Generation. EDUCAUSE e-book. Boulder: Colorado. http:// www.educause.edu/educatingthenetgen [viewed 9 Apr 2009, verified 25 Oct 2009].

Miller, S. M. \& Miller, K. L. (1999). Using instructional theory to facilitate communication in web-based courses. Educational Technology \& Society, 2(3), 106-114. [viewed 3 Oct 2007, verified 25 Oct 2009] http: / / www.ifets.info/journals/2_3/miller.pdf

Murphy, E. (2004). Recognising and promoting collaboration in an online asynchronous discussion. British Journal of Educational Technology, 35(4), 421-431. 
Neo, M. (2004). Cooperative learning on the web: A group based, student centred learning experience in the Malaysian classroom. Australasian Journal of Educational Technology, 20(2), 171-190. http:/ / www.ascilite.org.au/ajet/ajet20/neo.html

Nicol, D., Littlejohn, A. \& Grierson, H. (2005). The importance of structuring information and resources within shared workspaces during collaborative design learning. Open Learning: The Journal of Open and Distance Learning, 20(1), 31-49.

Nunan, D. (1990). The teacher as researcher. In C. Brumfit \& R. Mitchell (Eds.), Research in the language classroom. ELT Documents 133. London: Modern English Publications and the British Council.

Oblinger, D. (2005). Learners, learning and technology: The Educause learning initiative. EDUCAUSE Review, 40(5), 67-75. http: / / net.educause.edu/ir/library/pdf/erm0554.pdf [viewed 9 April 2009].

O'Donoghue, J., Singh, G. \& Dorward, L. (2001). Virtual education in universities: A technological imperative. British Journal of Educational Technology, 32(5), 511-523.

Roschelle, J. \& Pea, R. (1999). Trajectories from today's WWW to a powerful educational infrastructure. Educational Researcher, 43, 22-25.

Salmon, G. (2002). E-tivities: The key to active online learning. London: Kogan Page.

Schneider, D. K., Synteta, P., Frété, C., Girardin, F. \& Morand, S. (2003). Conception and implementation of rich pedagogical scenarios through collaborative portal sites: Clear focus and fuzzy edges. Keynote address for ICOOL (International Conference on Open and Online Learning), 7-13 December, 2003, University of Mauritius. [viewed 9 Apr 2009, verified 25 Oct 2009]. http:/ / tecfa.unige.ch/proj/seed/catalog/docs/icool03-schneider.pdf

Schwartz, L., Clark, S., Cossarin, M. \& Rudolph, J. (2004). Educational wikis: Features and selection criteria. The International Review of Research in Open and Distance Learning, 5(1). http:/ / www.irrodl.org/index.php/irrodl/article/view/163/244

Sikkel, K., Gommer, L. \& van der Veen, J. (2002). Using shared workspaces in higher education. Innovations in Education and Teaching International, 39(1), 26-45.

The Horizon Report (2007). New Media Consortium and The EDUCAUSE Learning Initiative. http:/ / www.nmc.org/pdf/2007_Horizon_Report.pdf [viewed 9 April 2009].

Thorne, S. L. \& Payne, J. S. (2005). Evolutionary trajectories, Internet-mediated expression, and language education. CALICO Journal, 22(3), 371-397. [verified 25 Oct 2009]

https: / / www.calico.org/a-137-

Evolutionary $\% 20$ Trajectories $\%$ 20Internetmediated $\% 20$ Expression $\% 20$ and $\% 20$ Language $\% 20 \mathrm{E}$ ducation.html

Wasson, B. \& Mørch, A.I. (2000). Identifying collaboration patterns in collaborative telelearning scenarios. Educational Technology \& Society, 3(3). http:/ / www.ifets.info/journals/3_3/c04.html

Wei, C., Maust, B., Barrick, J., Cuddihy, E. \& Spyridakis, J.H. (2005). Wikis for supporting distributed collaborative writing. Proceedings of the Society for Technical Communication 52nd Annual Conference. Seattle, WA. May 8-11, 2005. The Society for Technical Communication: Arlington, VA, USA. http: / / faculty.washington.edu/farkas/TC510/WeiWikisForSupportingCollabWriting.pdf 


\section{Appendix 1: The questionnaire}

\section{Part 1 - The wiki and interaction with your peers}

1. The wiki helped us to solve the PBL problem and achieve our goals more easily.

2. The wiki helped us develop small group skills that we need for teamwork.

3. The wiki helped us be more connected with our group members and with other groups.

4. The wiki helped us distribute the work better and more fairly.

5. The wiki helped us monitor each others' efforts and contributions more easily.

6. The wiki helped us assist each other better.

7. In the wiki we gave and received constructive feedback in the form of advice and encouragement.

8. The wiki helped us to initiate further activities.

9. The wiki helped us better acquire knowledge and skills.

10. The wiki promoted critical thinking.

11. The wiki helped us exchange information and ideas more easily.

12. The wiki helped us to jointly reflect on the progress of work.

13. The wiki helped us learn from one another.

14. The wiki helped us co-construct shared perspectives more easily.

15. The wiki helped us use English to discuss things.

16. The wiki provided us with a space for chatting.

17. In the wiki we commented and reflected on the wiki itself and its features.

18. The wiki helped me work more autonomously as an individual.

19. The wiki helped us work more autonomously as a group.

20. The wiki helped me to better define my self-identity in relation to the group.

21. The wiki helped us become more strongly defined as a group.

22. In the wiki we had the opportunity to compare our work with the work of other groups and we could better check if we were progressing well.

\section{Part 2 - The wiki and interaction with the English teacher}

1. With the wiki we were able to communicate more with the English teacher.

2. With the wiki we were able to communicate more efficiently with the English teacher.

3. With the wiki we were able to get more support and advice from the English teacher.

\section{Part 3 - The wiki and interaction with the resources}

1. Evaluate the usefulness of access to the wiki pages of other groups.

2. Evaluate the usefulness of the link to the English web resources (in the SideBar).

3. Evaluate the usefulness of the link to the Faculty website (in the SideBar).

4. Evaluate the usefulness of the link to the What is PBL? resource (in the SideBar).

5. Evaluate the usefulness of the link to the PBL timetable (in the SideBar).

6. Evaluate the usefulness of the link to the Agreement form (in the SideBar).

7. Evaluate the usefulness of the link to the Writing minutes resource (in the SideBar).

8. Evaluate the usefulness of the link to the Writing reports resource (in the SideBar).

9. Evaluate the usefulness of the link to the Assessment forms (in the SideBar).

10. Evaluate the usefulness of the link to the PBL blog (in the SideBar).

\section{Part 4 - The wiki and interaction with the wiki software}

1. The editing features contributed to better work in the wiki.

2. The features of adding pictures, documents and links contributed to better work in the wiki.

3. The feature of leaving comments on individual wiki pages (the Comments button) contributed to better work in the wiki.

4. The way the wiki pages and resources were interlinked contributed to better work in the wiki. 


\section{Appendix 2: The semi-structured interview questions}

\section{Initial questions}

1. For the record, could you please tell me your name?

Purpose: to identify the three interviewees

2. How are you? Has your holiday started yet?

Purpose: to relax the interviewees

3. Do you like using IT? How about other members of your group?

Purpose: to assess the students' liking of IT

4. Briefly describe your PBL experience.

Purpose: to find out thoughts (likes/dislikes) about PBL

5. How did you feel about working in a team?

Purpose: to find out thoughts (likes/dislikes) about team work, to ascertain if there were any problems within the team

\section{Questions about interaction with students in the wiki}

6. How did you* use the wiki to collaborate?

Purpose: to identify the ways the students used the wiki for collaboration and the factors that affected the use

- How often did you visit the wiki? For what purpose?

- How did you distribute the work in the wiki? Why?

- How often did you visit/edit your own wiki page? For what purpose?

- How often did you visit the other groups' pages? For what purpose?

- How often did you visit the blog? For what purpose?

- What enhanced/inhibited the interaction between your peers and other groups in the wiki?

ㅁ The features of the wiki?

- The public nature of the wiki?

- The character of the students?

- The technical skills of the students?

- That it was a requirement and was being assessed?

- That it was fun?

- Some other factor?

- What about the wiki would have to be changed for you to interact in it more?

- What enhanced/inhibited the communication/chat in English between your peers and other groups in the wiki?

- The use of the English language?

- The features of the wiki?

- The public nature of the wiki?

- The character of the students?

- The technical skills of the students?

- That it was a requirement and was being assessed?

- That it was fun?

- Some other factor?

- What about the wiki would have to be changed for it to be more appropriate for communication/chat in English?

7. What other technologies did you use to collaborate? (phone, email, Skype..., e.g. sending unfinished versions of the minutes for correction to your peers via email instead of editing them comfortably in the wiki)

Purpose: to find out if the students used any other technology which could perhaps better enhance collaboration 


\section{Questions about interaction with the English teacher in the wiki}

8. How did you use the wiki to communicate with your English teacher?

Purpose: to find out how the students used the wiki to communicate with the English teacher and the factors that affected the use

- How often did you communicate with your English teacher in the wiki? For what purpose?

- What enhanced/inhibited your interaction with the English teacher in the wiki? (in the Comments space and in the blog)

- The use of the English language?

- The features of the wiki?

- The public nature of the wiki?

- The character of the students?

- The technical skills of the students?

- That it was a requirement and was being assessed?

- Some other factor?

- What about the wiki would have to be changed for it to be more appropriate for interaction with the English teacher?

\section{Questions about interaction with the resources in the wiki}

9. How did you use the hyperlinked resources in the Side Bar?

Purpose: to find out how the students used the hyperlinked resources and the factors that affected their use

- What enhanced/inhibited your use of the hyperlinked resources in the Side Bar?

- The content of the resources?

- The quality of the resources?

- The need/lack of need to acquire specific knowledge/information?

- The way the resources were presented in the wiki?

- Some other factor?

- Are there any resources that you missed in the wiki?

\section{Questions about interaction with the wiki software}

10. How did you work with the wiki software?

Purpose: to find out how the students used the wiki software and the factors that affected its use

- How did you learn to work with it?

- What enhanced/inhibited your work with the wiki software?

- Who in your group edited the wiki the most? Why?

\section{Concluding questions}

11. If you could change anything about the wiki, what would you change to make it even more suitable for online collaboration? (e.g. leaving a comment (positive and negative feedback) on other groups' pages)

Purpose: to ascertain if there is something the teacher did not think about when designing the wiki

- Are there any features that you missed in the wiki? (e.g. a forum, a link to a page where students can post jokes or interesting things unrelated to PBL)

12. Is there anything you would like to ask or add?

Purpose: to clarify or add anything the interview did not cover

* In almost all the questions 'you' refers to all the group members

Vida Zorko MA Ed Tech \& TESOL, Lecturer in English, Faculty of Social Sciences University of Ljubljana, Slovenia. Email: vida.zorko@fdv.uni-lj.si

Web: http:/ / fdvenglish2pbl.pbworks.com/ http:/ / www2.arnes.si/ vzorko/

http: / / www.fdv.uni-lj.si/English/Teacher/Teacher.asp?id=246 